\title{
Education, Environmental Attitudes and the Design Professions
}

\author{
Traci Rose Rider ${ }^{1}$ and Jack Elliott ${ }^{2}$ \\ ${ }^{1}$ North Carolina State University, Raleigh, North Carolina \\ ${ }^{2}$ Cornell University, Ithaca, New York
}

\begin{abstract}
As the concept of sustainability continues to become more popular within society, a number of different professions are called on to help champion the movement. With the resource strain inflicted by the construction industry alone, dedicated architects and interior designers are important players in forward progress. Though many organizations and associations have been created to help the building industry embrace sustainability both practically and theoretically, the actual implementation of green building practices in construction has been minimal. The main focus of this study is to look at the influence of undergraduate education on designers' interest in sustainable design. Additional research interest was in environmental attitudes and the impact of interpersonal relations on those attitudes.
\end{abstract}

Self-proclaimed practitioners in the green building industry were surveyed through a specified email list of the U.S. Green Building Council. The survey was web-based and addressed issues including environmental attitudes, undergraduate education and professional training. Dunlap and Catton's widely-used New Ecological Paradigm scale was included to measure proenvironmental orientation of the professionals.

Contrary to the main hypothesis of the study, undergraduate education was not seen by subjects to be a fundamental force in the decision to concentrate on sustainability. A number of educational elements typically seen in environmental education, including interpersonal interactions, were mentioned by subjects as substantially influential and are therefore explored.

Conference theme: Education of future architects

Keywords: ethics, attitudes, design education

\section{INTRODUCTION}

"In the end we will conserve only what we love; we will love only what we understand; and we will understand only what we have been taught." Baba Dioum

Sustainability has existed in the design world for centuries. At times labeled vernacular, these buildings responded to regional and local elements throughout history without the convenience of central air conditioning and complex drainage systems. As time and technology progressed, however, humanity became increasingly separated from nature and designs lost the necessity to reflect their surrounding environment. Much of design education has followed a similar path, slowly veering off regional and traditional knowledge to follow technological advancements, mobile professionals and lifestyles.

For the purposes of this research endeavour, "sustainability" and "green design" will be used synonymously. While there is much discussion about these two terms and their relationships to each other, this discussion is outside the scope of this paper; the terms will be used interchangeably.

Some schools have kept sustainability in the curriculum through fundamental dedication, and though these classes are not described as "sustainable" in either syllabi or course descriptions, some schools have a long-standing reputation as a "green school." With this integrated process, the students are exposed to a more comprehensive view and understanding of the impact of sustainability on both the final design and the process itself. Other programs seem to view sustainable design as a specialization that would require additional classes to be added to an already full curriculum.

Undergraduate education is a powerful factor in the forming of design ethics; it can be an equally powerful force regarding environmental ethics. Through the strategic integration of sustainability into whole 
curriculum paths, students would begin to understand the interconnectedness between built forms and nature at an early stage in education, ingraining these ethics into the design process. With such an intense and longerthan-average curriculum, design programs have great potential to make an incredible difference in the direction of the ecological future of the design professions.

This study uses an online survey tool to address two of the most important foundational elements of design - sociology and education - through three distinct threads. First, Dunlap and Van Liere's New Ecological Paradigm Scale will be used to evaluate the environmental attitudes of current green design professionals. Second, the impact of undergraduate education as an influence on sustainability will be examined. Third, additional influences on pro-environmental attitudes will be reviewed and analyzed in conjunction with formal education. As important singular aspects of design, both sociology and education will be reviewed individually.

\section{SOCIOLOGY}

This study will create the argument that the environmental issues society faces are analogous to issues in the world of design and can be addressed through education and design training. Referencing Catton and Dunlap's New Ecological Paradigm (NEP) (Catton and Dunlap, 1978), which discusses foundational beliefs toward the environment, the importance of society's view of the environment in understanding the design profession will be illustrated through environmental sociology. Building on the parallel between the Human Exemptionalist Paradigm (HEP) (Catton and Dunlap, 1978) and the design field, similarities between the HEP and the foundation of education within the design profession will be explored, ultimately arguing that the design field is in dire need of a restructured paradigm, much like that outlined in the NEP.

Designers are, above all, both human and a part of society. Because of this underlying truth, both the history of environmentalism and influences on environmental attitudes must be looked at. Society's environmental attitudes have been addressed in the growing field of environmental sociology. There are understandably a number of shades of grey when discussing the field, but as growing organizations such as the Society of Building Science Educators, the AIA Committee on the Environment, the Association for the Advancement of Sustainability in Higher Education and others illustrate, there is something worth investigating as seen in the recent expansion and popularity of the views on the environment. This paper cannot do justice to the comprehensive works done on the topic of environmental sociology, but will attempt an overview for the sake of relation to the design field.

\subsection{Environmental Sociology and the NEP Scale}

The field of sociology has been well-established for centuries and throughout these years, sociology practitioners became comfortable within the field, allowing the evolution of assumed standards. Though these standard beliefs are never actually outlined, in the 1970's Catton and Dunlap felt that these assumptions had become prerequisites for the practicing of sociology and were dictating how scientists approached their topics. Because they now perceived the original root of the field of sociology to be primarily based on human centricity and a fundamental view that humans are exempt from ecological principles and limitations, Catton and Dunlap designated the traditional mindset as the Human Exemptionalism Paradigm (HEP) (Humphrey, 2002).

The HEP theory, which they feel dominates modern day society, is based upon a Dominant Western Worldview (DWW) (Buttel, 1992). The basic fundamentals of the DWW are: (1) People are fundamentally different from all other creatures on Earth, over which they have dominion; (2) People are masters of their destiny; they can choose their goals and learn to do whatever is necessary to achieve them; (3) The world is vast and thus provides unlimited opportunities for humans; and (4) The history of humanity is one of progress; for every problem there is a solution, and thus progress need never cease (Dunlap and Catton, 1980). Through this reasoning, the basic anthropocentric values of the DWW and the HEP are to blame for the current state of the environment. More significantly, in response to these traditional anthropocentric sociological theories, Catton and Dunlap created a "New Environmental Paradigm" (NEP) (Dunlap and VanLiere, 2000). The overarching intention of this creation was to identify core values of the environmental sociology realm that would not sway with the society's fickle interest in environmental issues. Catton and Dunlap's NEP revolved around the idea that humans are actually entwined in the circle of life where ecological laws cannot be overruled by human ingenuity.

When first created in the late seventies, the NEP environmental attitude scale itself addressed three proposed indicators of an environmental worldview: anti-anthropocentricism, limits to growth, and the balance of nature (Dunlap and VanLiere, 1978). In 1990 the original 12-question scale was revisited and adapted, with the addition of two new areas of concern: the possibility of an ecocrisis and the rejection of human exemptionalism (Dunlap and VanLiere, 2000). This new scale had fifteen questions and was found to be just as successful in the prediction of an ecological worldview while covering more topics. A number of studies on specific populations have helped to solidify the original findings that the scale denotes proenvironmental attitudes as well as establishing known-group validity (Pierce et al., 1992). Additional studies have supported predictive validity by illustrating a significant relationship between the NEP scale and a variety of intended behaviors and actual behaviors, both observed and self-reported (Edgell and Nowell, 1989). 


\subsection{HEP/NEP and the Design Practice}

The HEP/NEP debate is easily applied to the design professions. Paralleling the field of sociology, designers' actions and beliefs are historically based on underlying presumptions reflecting the HEP view as stated earlier. Examples include the unchecked harvesting of forests, extracting of minerals for construction materials, and tearing down buildings no longer perceived to be attractive - only to replace them with other equally-dated structures likely to be torn down later. Though there are no direct correlations to the design professions found in the NEP literature, the foundations of the NEP translate easily. In sociological terms, non-green, conventional designers would be advocates of the HEP point-of-view. The market is the HEP-type designer's primary concern; demand is the ultimate design authority. In line with the Dominant Western World view and HEP perspective as covered earlier, a resource become scarcer, cost rises, and human ingenuity creates alternatives.

The HEP/NEP paradigm shift has been applied to a number of specific populations and could be applied to the design field. While no studies have been found to use the NEP scale on the design and construction professions, a number of the questions used within the scale can arguably relate directly to the field. For example, Statement Two in the NEP survey, "Humans have the right to modify the natural environment to suit their needs," directly addresses the very purpose of the design profession. While Dictionary.com has the definition of the term architecture as "the profession of designing buildings, open areas, communities, and other artificial constructions and environments," it is easily argued that in order to do this the profession is directly modifying the natural environment. Statement Four, "Human ingenuity will insure that we do NOT make the earth unlivable," can be translated to speak directly to technological advancements in the building industry. In Statement Six, "The earth has plenty of natural resources if we just learn how to develop them," references issues in design and construction including forestry management and energy conservation. By viewing these questions through an architect's lens, it is apparent how the HEP/NEP debate could be applied to design.

\section{EDUCATION}

The environmental education movement has its foundation in rural and local studies in the 1960's (Sterling, 2001). The term "environmental education" became popular in the 1970's, and began to encompass the ethical, political and urban issues that had been previously left to other fields. The 1980's wrapped global issues into the field while the 1990's allowed "environmental education" to be grouped with other movements looking to education for change, such as social equality. Some researchers and experts believe that traditional education is based on an outdated set of cultural beliefs and assumptions with an anthropocentric viewpoint and that a shift to environmental communication and education can be a catalyst for change (Bowers, 1995). In 1987, the World Commission on Environment and Development published The Brundtland Report, more commonly known as "Our Common Future," which helped to fuel change in education by articulating a unified world view and a global problem.

Public schools and higher education have been identified by many as a critical leverage point for change in environmental thinking. Some argue that the fundamental flaw with this is that the majority of education is primarily based on outdated assumptions and values, as noted above. Sterling (2001) claims that traditional education is behind the times in a number of ways: (1) it takes a "fundamentally mechanistic" view of the world; (2) it is primarily ignorant of issues concerning sustainability; and (3) it is uninformed of the growing ecological thinking that intends to more fully integrate humanity with the environment. In an effort to change the foundational emphasis and assumptions of education, much like the New Ecological Paradigm in sociology (Catton and Dunlap, 1978), new goals and values must be established. As the field of sociology was perceived by Catton and Dunlap to hold to anthropocentric views as an outdated foundation, the educational field is considered by some to be functioning on outdated fundamentals as well. In line with adjacent popular sociological theories, education is predicated on the assumption that human ingenuity will always prevail. Similar to the discussion on traditional education, much of the design curriculum has been established and accepted for decades at the very least, without much change in perspective. Design foundation classes revolve around perspectives, sight lines, traditional materials and traditional construction. Rarely are there required classes including ecological connections and sustainable design elements.

Sustainability education is felt by some to not have the goal of creating throngs of environmentalists, but to implement lifelong learning as well as civic, social, emotional and academic competencies, creating a better world at all levels in the future (Santone, 2003). Some elements addressed are critical thinking, transformative learning, participatory education, systematic education, ownership of learning, informal education and knowledge of place. While there is a wide range of literature on each of these individual subjects, not all can be addressed in this scope though many can easily be applied to design education.

\subsection{Design Education}

This paper supports the position that modern designers have historically envisioned themselves as separate from environmental problems, choosing to believe that the task at hand is, at a fundamental level, only an issue of composition and space formation. The primary concerns for design professionals typically hinge on two facets of design: the creation of spaces to enhance productivity through adjacencies, circulation and square footage and the aesthetics and composition of the proposed space. 
It should be acknowledged that these statements seem overly jaded; design professionals often perceive themselves to have an enriched sense of duty beyond those stated above, which may be social responsibility, public design or improving the well-being of users. It is not too much of a stretch, however, to state that the typical designer is concerned primarily with the human relationship to the built-environment, not the builtenvironment's relationship to nature. This indirect defiance has been referred to as the "Ostrich Syndrome" in the business world, insinuating that professionals bury their heads to continue with their work, without disruption (Hasan, 1993); the thought being that if the professional is unaware of environmental problems to which they are contributing, there is no need to take steps to change ingrained habits. With these established behaviors come the loss of both the desire and at times the ability to question daily, habitual choices.

Many design education programs remain basically unchanged because they may be seen as beyond reproach and too entrenched in tradition. Though the history and reputation of conventional American design schools is important, it will be assumed that readers of this article are well aware of challenges and benefits of established paradigms such as breadth of classes, lack of electives, concentrated focus and technical expertise.

While there has been little research addressing sustainability within design education, a few articles and examples have been published addressing the topic. A yearly survey done by Metropolis Magazine in 2003 states that while it is fundamentally true that grassroots environmentalism is having an effect on design and architecture, the integration of sustainability into formal education leaves much to be desired. It was reported by educators that: two out of an average of eleven studios were dedicated to sustainablity; twenty-seven percent said that between one and three required courses were focused on sustainability; forty-six percent were attempting to thread sustainability through the foundation of their program; and that funding was the biggest barrier to integrating sustainable design into the curriculum (Szenasy, 2003).

The topic of implementation pertaining to environment-based education in design programs is entirely too broad to tackle in this scope. However, some educational elements highlighted in the environmental education discussion, such as participatory education and informal influences, are appropriate to explore in relation to design training and environmental attitudes. By investigating the influences of established green building professionals, it will be possible to begin to identify some of the most effective means of sustainable education, as well as those elements that are consciously perceived to make design professionals to "go green."

\section{METHODOLOGY}

Three main objectives have been identified in this study. The first goal is to evaluate environmental attitudes of established green building professionals through the use of the NEP Scale. Second, determine the most effective factors in steering design professionals towards sustainability. The third goal is to look at the impact of design education on a professional's decision to go green. Each hypothesis was created to address different levels of influence on sustainability. The hypotheses of the current study are as follows:

HO1: Design professionals interested in green design will score high on the New Environmental Paradigm scale.

HO2: Design professionals interested in sustainable design will attribute their interest to the design education that they have experienced.

HO3: Personal interactions, such as attending a speech or the enthusiasm of a coworker, will be the most powerful influence second to formal education.

\subsection{Research Design}

The design of this study is a simple case study design, concentrating on the influences of a single group of environmentally-friendly designers. In efforts to maintain a manageable study, no second control group was implemented. The intention was to look at the influences that effect interest in sustainable design, as well as the possibility of an interaction of education. Because of the need to reach a large number of people across different locations, an online survey was determined to be the best medium for this study.

A short preliminary survey pertaining to undergraduate experiences and influences was developed and administered to just fewer than two hundred students and young professionals already interested in the green building movement. The preliminary survey was administered at Greenbuild, the U.S. Green Building Council's annual conference and expo held in Portland, Oregon, November 9-12, 2004. Because of the general scope of the survey, questions were both simple and broad. Five of the questions were simply for categorization. The total number of preliminary surveys handed out is unknown. Of the thirty-six responses to fully complete the survey, $86 \%$ said that they had an undergraduate experience dealing with green design. Of those, $61 \%$ claimed that that experience was integral in turning their interest towards a sustainable trajectory. Seventeen of the respondents were in either Architecture or Interior Design and of these respondents all claimed that they did have an undergraduate experience in green design. Of those respondents, nearly $59 \%$ of designers cite this undergraduate experience as integral to their interest in sustainable design. In addition to the correlation to undergraduate studies, other influences on their interest in sustainability were noted to be exposure to influential speakers and books; first hand experiences and service learning; upbringing and peer enthusiasm. 
A Likert response scale was chosen because of the familiarity of the scale to the general population, in addition to the perceptual ease of completing the survey. By allowing for intensity of attitude expression through possible selections of "agree" or "strongly agree," a greater variance of results is received (Kerlinger, 2000). When the pool of questions was sufficiently compiled, the second version of the survey was sent to a small sample of professionals indicative of the larger target population to be studied. Thirteen responses were received. A blank section for feedback was provided on the survey for additional insight, and the survey was altered in light of these comments and was narrowed to forty-three questions. The well-known study performed in the late seventies by Dulap and Catton, which was created in an attempt to measure the popularity of an ecological worldview (Catton and Dunlap, 1978), was referenced and the full fifteen questions were added to the survey.

The final survey consisted of fifty-five questions allocated in the following way: fifteen questions addressed environmental attitudes per the NEP scale; eleven questions addressed general lifestyle choices and background; twenty-four questions addressed both education and professional experiences. The final question was a blank allowing for respondent email identification if they wished to be compensated through a drawing.

The final email survey was presented to a representative sample of green building professionals in April 2005. The survey was administered through a specific email from the Chapter Coordinator of the U.S. Green Building Council (USGBC), reaching approximately 200 professionals, specifically leaders of local USGBC chapters around the country. The leadership and members of each of the chapters are quite diverse, encompassing design firms as well as press, schools, financial firms, manufacturers and other interested parties. One follow-up request was sent out the following week. A total of sixty-eight survey responses were recorded through WebSurveyor's Desktop online program.

\section{RESULTS}

The overall environmental position of this group of green professionals on the attitude spectrum as outlined by the NEP scale will be assessed. Common view-points, as well as peculiarly uncommon view-points, will be noted as well. Thirty-five of the sixty-eight respondents indicated that they were either architects or interior designers, for $51.5 \%$ of the total responses. This narrowed population will be the overall focus of these results.

The overwhelming majority of green building professionals responding to the survey scored high on the NEP Scale, as did the group of proclaimed green design professionals. Each of the responses to the fifteen line items indicates the majority of respondents endorse ecologically-friendly positions and beliefs. For questions concerning Limits to Growth, the majority of subjects responded in line with a pro-ecological view. For questions addressing anti-anthropocentricism, the majority of subjects again responded in an environmentally friendly manner. While responses to certain questions were indicators of pro-environmental values, other similar questions were less polarized, with just 30.3\% either agreeing or agreeing strongly with the statement regarding humans' right to modify the environment. Two questions addressed the rejection of exemptionalism and showed that the vast majority of designers are in agreement with pro-environmental views. However, when addressing human ingenuity responses spread across Agree, Unsure, and Disagree with approximately $30 \%$ in each.

The responses were most uniform for questions addressing the fragility of nature's balance and the possibility of an eco-crisis. When pertaining to nature's fragility, at least $75.8 \%$ of the total subjects indicated proecological attitudes in all three. For questions addressing the possibility of an eco-crisis, the overwhelming majority indicated a pro-environmental stance with at least $87.9 \%$ in agreement. While a few indicated that they felt unsure, only one individual answered against pro-environmental values in all three of the questions.

Of the thirty-five respondents in this designer group, the majority finished their undergraduate work between 1980 and 2000. Seventeen (41\%) indicated that education was not a factor in their interest in sustainable design. Only $34 \%$ cited some form of higher education as an influence. Of those, $83 \%$ felt that their undergraduate experiences were more formative than their graduate experiences. Sixty percent of respondents disagreed to some extent that sustainability was never addressed in their undergraduate education.

Only one of the responding designers indicated choosing their place of undergraduate education based on environmental view and sustainability reputation. Sixty-eight percent disagreed that sustainable reputation had anything to do with their choice in what program to attend. Only $5.9 \%$ of the total sample of sixty-eight selected their formal education based on the green reputation of the school. Eleven percent responded that they strongly agree that they entered the program with an intent to study green design; $23 \%$ simply agreed; $29 \%$ replied neutral; $23 \%$ disagreed; and $11 \%$ strongly disagree. Only one respondent of the designers indicated agreement with the statement that their school addressed sustainable issues more in curriculum than other design programs would have. The other $97 \%$ felt that their programs were on par with the environmental pulse throughout the rest of the design schools at the time.

The majority of responding designers (65.7\%) do not attribute their interest in sustainability to education at all. Of the remaining $31 \%$ that do credit their education as a factor in their environmental views, $63.6 \%$ cite an elective class as the spark of interest. Of the $40 \%$ of respondents indicating that a class did influence them, $61.5 \%$ claimed that the class was design related, while $38.5 \%$ said it was an elective outside of the design school. Ten of the designers (28.6\%) could point out a specific professor that was an influence on their green building position. This is consistent with $30.4 \%$ of the total respondents who could also identify one instructor 
that they felt made a difference in their position. When asked about the inclusion of environmental authors such as Thoreau, Emerson, John Muir and Rachel Carson, 91.4\% of designers agreed to some extent that these authors should be included more in design curriculum.

\subsection{Professional Interests \& Additional Influences}

Two of the thirty-five designers (5.7\%) did not view themselves as green designers, while the remaining thirtythree did. In the whole sample of sixty-eight subjects, twelve (17.4\%) did not perceive themselves to be "green." One individual gave a neutral answer to the question addressing sustainable issues as honestly too bothersome to address on a daily basis. The respondents, both overall and only designers, unanimously agreed that they have the ability to make a difference in the environment through their profession.

None of the responding designers indicated that they were interested in sustainability due to marketability, professional reasons, internships, service learning, and recreation interests. The remaining proposed factors are fairly equal in response: two individuals $(5.7 \%)$ indicated that they were influenced by a speaker; three (8.6\%) were influenced by travel; five $(14.3 \%)$ were influenced by formal education; five others $(14.3 \%)$ were swayed by attending a conference; three more (8.6\%) were influenced by a book or article; two $(5.7 \%)$ credit a co-worker while one $(2.3 \%)$ credits an acquaintance; five more $(14.3 \%)$ tribute their upbringing; and eight (22.9\%) attribute their interest in sustainability to other factors altogether.

\section{DISCUSSION}

While the surge in green design is at an all-time high, there is still far to go in the movement. The results of the survey indicate that those design professionals involved in green design are fundamentally dedicated to sustainability. All responses suggested that the interest in sustainability was sincere and heart-felt, as opposed to the possible interest for a career boost.

\subsection{Hypothesis One - NEP}

In reference to the NEP scale portion of the survey, the results reinforce earlier findings that special interest groups and environmental organizations score high on the NEP Scale (Edgell and Nowell, 1989). Proving Hypothesis One correct, the results illustrate pro-environmental tendencies within the group.

There are questions whose responses were not as significantly aligned with the pro-environmental indicators as the rest of the survey. Question six, which refers to the development of natural resources, was one of these questions. This may be the case due to the pre-determined nature of architecture and design as referenced earlier in the background section, which assumes that additional resources are ultimately needed to continue the growth of the built environment. Question two was also less clear, and may be attributed to the same reasoning; referring to the right of humans to modify the natural environment to suit their needs, this question addresses the very premise of architecture as currently understood.

Question four, speaking to the rejection of exemptionalism and human ingenuity, returned the most uniformly spread responses from the group of designers. This may be the case because designers are trained to be creative and rely on ingenuity to problem solve on a daily basis. This ingrained perception within the designer population may be at odds with their fundamental environmental positions, resulting in the spread out responses.

The responses were most uniform for questions addressing the fragility of nature's balance and the possibility of an eco-crisis. This may point to a lack of ecological knowledge in the design field, resulting from the narrow focus of design education. It could also indicate the perception that there is little interaction between the design fields and nature's balance and an eco-crisis, while the topics of anthropocentricism, limits to growth and exemptionalism may likely have a direct effect on the design professions.

\subsection{Hypothesis Two - Education}

Contrary to Hypothesis Two, the vast majority of green professionals did not attribute their desire to concentrate on sustainability to their formal education. There is some unclear data that should be looked at more carefully. While sixty percent of the respondents felt that sustainability was addressed in their undergraduate education, forty percent did not feel that their education affected their environmental ethics in relation to green building. This could be attributed to self-selection into the program for those already environmentally friendly or possibly credited to a delayed effect where the teachings were not fully realized until much later in their professional development. Similarly, it could be due to the differences in programs, teaching styles, curriculums or any number of other small differentiations in the schools. Regardless, education is not being identified by the majority of green designers as an influence on their interest in sustainability.

The large percentage of subjects that claim they did not choose their school based on sustainable reputation shows that many other elements of design education were playing a larger role in selection. This could be attributed to the possibility that not many programs had classes based in green design during the 1970s, 1980s and 1990's when many were entering school, or were simply not called them by those terms. A number of schools have a well-known reputation for being sustainable, but would be difficult to quantify for a researcher when looking at course titles, online descriptions and other easily accessible information. It may also be attributed to the fact that green building programs may not have existed at the time. 
Of the thirty-five percent that did cite some form of higher education as an influence, the majority (83.3\%) felt that their undergraduate experiences were more formative than their graduate experiences. This speaks to not only the importance and impact of undergraduate design curriculum, but also the possibilities for influence on the profession if there were a major swing in sustainability curriculum in formal design education.

Results indicate that the majority of those affected by classes were influenced most by electives and not by design classes. This points toward a lack of green classes offered as a required part of the curriculum. This confirms previous surveys on sustainability in design schools where $27 \%$ claim having one to three classes required (Szenasy, 2003). Other subjects indicate the importance of design related classes, which emphasizes the significance of applicability and practicality. Classes such as service learning and participatory education that are informative and explicitly illustrate the implications of green building elements are found to be most productive and useful. Still other subjects indicated that the class most influential was outside the design school, lending support to the importance of systems thinking and interdisciplinary learning as covered previously. While the theme of the overall responses indicates that formal education did not affect the professional choice to think green, the overwhelming majority of respondents advocated more environmental readings during undergraduate education. While the remaining did not advocate it, neither did they disagree with it. This would indicate that these designers felt that environmental readings would have been more beneficial in retrospect, and would be suggested for future courses in all design programs.

\subsection{Hypothesis Three - Personal Interactions}

Data supports Hypothesis Three by showing that personal interactions are important in emphasizing environmental attitudes. By combining interactive means such as travel, conferences, speakers, co-workers, and personal acquaintances, results show that $37 \%$ of professionals credit these methods of moving them toward sustainability, as opposed to the 14\% that actually did credit higher education. In reality, a number of subjects indicated "other" in their responses, which was seen to include items such as "girl scouts," "travel combined with education," and "observation." If these specific elements were teased apart in more detail, it seems that they would likely fall into the categories of either education or personal interaction. Though it was left out of this calculation, it may also be appropriate to include both "reading a book/article" and "upbringing" within the personal interaction category.

\subsection{Limitations of Current Study}

While the scope and parameters of the current study were selected for their ability to provide a wide range of data, a number of factors in the present research design are limiting. The limitation of personal bias must first be acknowledged. As a design professional deeply interested and dedicated to sustainable design, as well as deeply believing in the importance and impact of education, personal bias of the researcher may have had an effect in either the creation of questions or in the translation of responses.

By focusing on just one of the factors addressed in this study - environmental attitudes, formal education or environmental influences - research efforts would be able to dig deeper into each of these facets, likely revealing more concrete findings. While combining the three components into one research design does allow for additional relationships to be reviewed, it also has the potential to confuse the subjects. Another limitation is the sample size returned from the online survey, as well as the manner in which it was administered. Though the overall number of returned surveys was decent at sixty-eight, only thirty-five of the respondents fell into the categories of architect or interior designer, the two fields that were being targeted in the study.

A more representative sample would also help to increase the number of subjects that completed their study in the year 2000 or later, which is when the "sustainability" buzz word would have become most integrated into curriculums. Because the majority of subjects graduated between 1980 and 1990, results will reflect specifically what was happening historically in the field at that time. A better distribution of subjects would help to filter out that influence. Also, by concentrating on only a handful of schools and programs, some of the finer elements pertaining to classes and influences could begin to be teased out of the data.

\subsection{Future Research and Implications}

To thoroughly investigate the scope of this research, a number of additional studies should be conducted specific to each of the factors addressed. Research concentrating particularly on environmental attitudes within design as outlined through the NEP should be conducted (Dunlap and VanLiere, 1978). A comparative analysis of environmental attitudes between populations of designers should be performed. The NEP Scale could also be used on a larger sample of design professionals, with established green design professionals as a control group.

In light of these NEP survey results, the question then turns toward the actions and behaviors of these green design professionals within the workplace. While the group as a whole does declare their allegiance to pro-environmental attitudes, this does not mean that they exhibit pro-environmental behaviors. Additionally, differentiations between pro-environmental behavior in private and professional lives should be considered.

Educational influence can be researched further in a number of different ways. Students could be given the NEP survey as they enter design programs and again when they graduate; this would measure any change 
in environmental attitudes while at school, providing a measurable aspect of the education experience. Detailed, objective program profiles should be created addressing green design, incorporating the program's dedication to sustainability. This could include an alumni tracking and comparison study focusing on the tracks and positions of alumnus of different programs, while attempting to discern the differences in environmental attitudes of the alumni. Closely related, the NEP Scale could be administered in conjunction with different levels of programs and types of curriculums. This would be helpful in understanding the true effects of university level design curriculum on environmental attitudes and behaviors by contrasting responses from entry-level cohorts. A list of the most effective school programs could also potentially be developed. Additionally, this vein of research could be easily extended into the realm of continuing education for both architects and interior designers.

Of great importance is the guidance that these results provide and the future research within environmental education and design. A future study should address the relationship between environmental education methods and design programs, highlighting effective ways to introduce sustainability to students regardless of the specific curricula and different programs. As noted previously, a number of informal and nontraditional efforts have a substantial impact on undergraduate students relating to the environment.

\section{CONCLUSION}

Contrary to Hypothesis Two, most green design professionals did not credit their undergraduate education with turning their professional interests toward sustainability. Though many programs and departments indicate that they do offer courses in sustainability and environmental design (Szenasy, 2003), graduates themselves are not feeling the effect. While many respondents did not credit their education with their interest in sustainability, a substantial portion of subjects cited electives as important in the forming of environmental ethics during school. One possibility is that there were not many required sustainable design classes available, making electives the only option, either within or outside the department.

Because of the responses pertaining to electives and education, it is believed that education has the possibility of being more important in turning toward sustainability than an initial glance as the results from this study seem to indicate. The subjects responded in great numbers to suggestions for design education reform, indicating a true interest and allegiance to design education. Suggestions, such as the reading of more environmental literature in the classroom, were met with overwhelmingly positive response. The combination of these responses lead to a sum greater than all the individual parts; while education itself is not ranked highly as a factor, each of the individual elements received high marks.

The results of this study indicate that the individual elements of environmental education, most likely found in electives, are what graduates remember in relation to environmental ethics in design education. This study supports the fact that a number of individual elements could be successfully incorporated into design education to encourage environmental behavior. The combination of various educational methods in design education provides undergraduate programs the potential to deliver necessary environmental knowledge, values and impact that future professionals in the design industry desperately need. By increasing the exposure to these different alternatives, current and future professionals alike will be reminded that design is not simply about aesthetics and functionality. With it comes that higher calling, to create healthy buildings not just for the users but also for the natural environment, allowing future generations to meet their resource needs as we are currently able to meet ours.

\section{REFERENCES}

Bowers, C. A. (1995). Educating for an Ecologically Sustainable Culture: Rethinking Moral Education, Creativity, Intelligence, and Other Modern Orthodoxies. Albany, State University of New York Press.

Buttel, F. H. (1992). "Environmentalization: Origins, processes, and implications for rural social change." Rural Sociology 57: 1-27.

Catton, W. R. and R. E. Dunlap (1978). "Environmental sociology: a new paradigm." American Sociologist 13: 41-49.

Dunlap, R. E. and W. R. Catton (1980). "A New Ecological Paradigm for a Post-Exhuberant Sociology." American Behavioural Scientist 24(1): 15-47.

Dunlap, R. E., K. D. VanLiere, et al. (2000). "Measuring Endorsement of the New Ecological Paradigm: A Revised NEP Scale." Journal of Social Issues 56(3): 433.

Edgell, M. C. R. and D. E. Nowell (1989). "The new environmental paradigm scale: Wildlife and environmental beliefs in British Columbia." Society and Natural Resources(2): 285-296.

Humphrey, C. R., T. L. Lewis, et al. (2002). Environment, Energy and Society: A New Synthesis. Belmont, CA, Wadsworth-Thomson Learning.

Pierce, J. C., M. E. Steger, et al. (1992). Citizens, political communication and interest groups: Environmental organizations in Canada and the United States. Westport, CT, Praeger.

Santone, S. (2003). "Education for Sustainability." Educational Leadership(December 2003/January 2004).

Sterling, S. (2001). Sustainable Education: Re-visioning Learning and Change. Bristol, Schumacher Society. 